\title{
Russian Higher Education in XXI Century: Traditions and Trends
}

\author{
Elena Pokazannik ${ }^{1}$ \\ ${ }^{1}$ Don State Technical University, Faculty "Psychology, Pedagogy and Defectology", \\ 344000 Rostov-on-Don, Russian Federation
}

\begin{abstract}
The article covers the issue of preservation and rethinking of traditions in present-day Russian higher education. The formulation of paradigm of higher education in Russia at the present stage and the actual trends related to the formation of this paradigm are discussed. The main issues are highlighted, and brief problematic comments are given for each. The absence of the single concept of Russian higher education development is discussed; the values and quality criteria are defined along with traditions (basic milestones) that determined the image of national higher education during Soviet period; the need for adaptation of the teaching community to the modern conditions and requirements is stressed.
\end{abstract}

\section{Introduction}

There cent decades in the Russian higher education can be safely called crucial. The beginning of the 21 st century turned out to be a reference point for the university system, starting a long series of transformations, innovations, rethinking, and dramatic breakdowns. Many researchers talk about searching for and even finding a new paradigm. Many questions are raised in the process of this very painful "acquisition". Was this paradigm initiated "at the top", or is it a result of stepwise evolutionary development and orderly transition of accumulated quantity into quality? Whatarethe new values and the criteria of this quality? Which basic milestones should be preserved, and which ones have become obsolete?How do we - the teaching community, - quickly and painlessly adapt to the changing conditions, that have been symptomatically called "challenges" more and more often.

\section{Results and discussion}

It is impossible to cover the secomplex and controversial issues in a brief article, so we will define the most critical aspects that require further discussion and elaboration. 
1. Higher education paradigm. What is it today and is it possible to talk about the emergence of a certain collective awareness of the need for a unified approach to education, at least at the highest, system-forming level? A vast variety of opinions on that matter can be found in research publications today. Smart-education[1], the formula "from "teaching" - to "learning" format in education", transition to "market oriented" education system [2], globalization and internationalization, - and as a counterweight - a concept of education as creativity, humanization, preservation of national and cultural identity [3], merging of science and education [4] are all called a new paradigm. Practically all researchers acknowledge the absence of aunified concept, identify a large number of problems and inconsistencies, stress multi directionality of the efforts of state agencies and professional community, and propose various models and approaches.

Formally, the change of paradigm in Russian education was marked by signing the Bologna Declaration on European Higher Education Area in 2003, which necessitated unification of requirements to the structure and content of higher education and transition to the proverbial two-level system of "bachelor - master" degrees. However, having implemented series of changes during the decade after introduction of Bologna system, the authors of the changes and all participants of the education domain realized that the new principles of organization of teaching process in higher education must be supported by the most substantial changes in content, while their vector has yet to be finalized.

Today, the educational standards are being "tied" to professional ones, which indicates the state's effort to reorient education to the specific needs of the labor market and economy, but the content of these regulatory documents often turns out to be formalistic, ill-conceived and hardly applicable in real practice. While the wider independence of universities is declared in selection of educational trajectories, the strict requirements of regulatory documents and controlling agencies practically eliminate these possibilities. During the recent years the need for adjustment of many provisions of Bologna system, and their adaptation to conditions and traditions of Russian higher education became evident. Inpractice, many representatives of higher education community see adaptation as a return to the old system of specialist training, which is hardly possible or advisable today, while the RF Ministry of Science and Education changes the policy every time a new minister takes up the post (see comparative table in[2, p. 74]).

2. Values and quality criteria of the contemporary Russian education. One of the key problems here is the contradiction between the expectations and criteria by which a higher education institution, an educational program are evaluated by various "expert" communities - students, employers and state agencies that manage the education system. Labor market demand is the basic trend for prospective students and state agencies, while the criterion of education quality is readiness to perform specific professional tasks ${ }^{1}$. However, the employers more and more often comment on detachment of graduates' theoretical knowledge from future professional activity, and focus on soft-skills that equip young specialists with "soft" sub-professional social skills, rather than on hard-skills which, in their opinion, can be taught "on-the-job" during 1-2 months. Anothertrend, which is in creasingly more often called an accomplished fact for employers and a nearest perspective for universities, is the growing demand for so-called "comb-shaped" people able to integrate knowledge and skills from different disciplines, rather than T-shaped ones with deep basic knowledge and skills in a single area (see more in[5]).

In contrast to the obvious reorientation of education to the technological and social components, awareness is growing in the professional community of the dangers of such one-sided utilitarian approach to university education. Given the obvious importance and

\footnotetext{
${ }^{1}$ There is one significant difference - the RF Ministry of Science and Education focuses on specialist demand by national labor market, while the graduates often estimate the perspectives of foreign employment.
} 
necessity, this practice-oriented training should be supplemented by fundamental knowledge that forms the student's integral system of knowledge about society, the foundations of a research culture, creative inquisitive thinking, the ability to set and solve non-standard tasks. The separation of basic higher education from science leads both to degradation of science itself - it has no source to be fueled by young researchers, and to devaluation of the status of university graduates to the level of simple "cogs in the mechanism" of enterprises and institutions. The idea of "learning, not teaching" is correct as such: it leads to the path of active self-development; however in practice, it often turns into do-it-yourself memorization of a minimal set of standard patterns, operations, and functions from textbooks and electronic manuals. Why is it happening? There are several reasons, and one of the principal causes is an active policy of yuthification of the teaching community and specialists in administrative structures and state agencies. This trend leads to washing out of experienced specialists, their replacement with more mobile, more manageable, and, importantly, lower-pay successors. With this one-sided approach, the self-development of today's students is often managed by yesterday's graduates, still lacking the necessary knowledge and experience. Departments, divisions and entireenterprises and organizations are now managed by people without sufficient professional and personal experience. More and more often, the "lieutenants" are entrusted with management decisions, rather than "colonels" and "generals". The outcome is evident.

3. Basic milestones. The basic milestones that determined the path of student's professional development in the Soviet period, regardless of specialty - be it a chemist or a lyricist, were strict regulations and stability in the content of education, its ideological and academic nature, as well as clear prospects for employment and professional growth. Significant social-political and economic changes that took place in Russiain recent decades, emergence of new technologies, globalization of all processes (economic, educational, scientific, cultural, etc.), integration of scientific and educational communities in the single internet space - all that could not but impact the foundations of Russian higher education. The changes affected the content of education (the search for optimal requirements still continues), the relationship with science, employment prospects, and creation of unique educational trajectories in constant correlation with rapidly changing employers' needs. But, despite all the changes, sometimes very significant and even revolutionary, the higher education system in our country today is not yet ready to respond flexibly and quickly to current demands of the labor market and even more so, of academic science.. The traditions that defined the identity of a national university in the Soviet period were largely determined by the laws of a planned economy, the centralized system of scientific research management, and an ideological component. Obviously, attempts to appeal to preservation of such traditions are unfounded. The traditions that really should be preserved lie in the plane of professional ethics of the university instructor: responsibility for the content of the taught disciplines and the outcome of teaching, constant selfdevelopment, involvement in active research work and presenting its results at reputable scientific conferences. Despite the obvious need to preserve such traditions, they are often substituted by the pursuit of formal indicators - both from the administration of universities and from the instructors themselves.

4. Thelast issue - the need for teaching community to adapt to changing conditions obviously follows from the fore going. It is natural to assume that all higher education system transformational processes are controlled by active participation- both positive and negative, - of academic staff. Their attempts to preserve the best and bring the new to traditional forms of teaching, to offer modern, often non-standard formats of knowledge transfer, and to meaningfully rethink the transmitted information are of the positive nature. Negativity is expressed in rejection of any changes, the desire to keep the established models unchanged, and to "stabilize" the presumably necessary volume of knowledge, to 
protect themselves from the efforts associated with the modernization of education. The diversity of functions of a modern university instructor and the need to multitask have already cut off a fairly large part of the older generation - professors of the so-called "old school". Their successors - younger colleagues who studied in the post-perestroika period, difficult for higher education, were no longer able to adopt traditions and foundations, and still had no opportunity to learn the new and in a new way. Loss of the quality of their education naturally led to a decrease in the overall academic level of the teaching community, which has become the most acute today's problem.

\section{Conclusions}

Summing up, it should be noted that the system of education as a whole - from pre-school and elementary to so-called "post-graduate" levels - is an extremely complex organism, multi-component and non-uniform both in goals and tasks and in outcomes. To simplify, the education system can be compared to a tree: its trunk is the secondary education, thicker branches - secondary vocational and "basic" higher education (bachelor's degree); twigs and leaves - higher education of the second and third levels (master's degree, post-graduate studies), additional vocational training, doctoral programs.... The trajectory is clear: from basic un ambiguity, stability and predictability to variability, individualization, interdisciplinarity, in-depth studies and specialization. The today's challenge for all participants of educational relations and the structures that regulate these relations, is a flexible response to changes while carefully preserving the accumulated experience. "Ad utrumque paratus"2.

\section{References}

1. O. Lomakina, T. Gustomyasova. Modern Paradigm of Higher Education Development: Smart-education// Language, Culture and Professional Communication in Today's Society. Materials of IV International Scientific Internet-Conference of G.R.DerzhavinTGU (2015). http://www.tsutmb.ru/nayk/nauchnyie_meropriyatiya/int_konf/mezhdunarodnyie/y azyik,_kultura_i_professionalnaya_kommunikacziya_v_sovremennom_obshhestv e/sekcziya_2._pedagogika/sovremennaya_paradigma_razvitiya_vyisshēgo_obrazo vaniya_smart_education)

2. E. Shirinkina. Modern Paradigm of Higher Education Reform // Herald of Udmurtia University "Economy and Law", 27,69-76(2017)

3. V. Artemova, Ya. Filippova. Paradigm of Modern Education: Socio-cultural Aspect // Herald of N.I.Lobachevsky Nizhny Novgorod University. Series: Social Sciences. 1, 368-373 (2004)

4. M. Romantsov, G.Danilenkova, I.Melnikova, L. Goryacheva. Paradigms of Higher Education in Modern Conditions // International Journal of Experimental Education, 11, 17-24 (2011)

5. Interview with Anastasia Butrym, Director of the British Higher School of Art\&Design // https://moskvichmag.ru/lyudi/direktor-britanki-anastasiya-butrym/

${ }^{2}$ Prepared for both (Lat.). 